RUNNING HEAD: ENGAGEMENT BEYOND THE MIRROR

\title{
ENGAGEMENT: LOOKING BEYOND THE MIRROR TO UNDERSTAND \\ ACTION UNDERSTANDING
}

\author{
Vasudevi Reddy ${ }^{1}$ and Sebo Uithol ${ }^{2,3}$
}

${ }^{1}$ Department of Psychology

University of Portsmouth

This is the peer reviewed version of the following article:

King Henry Building

Reddy, V. and Uithol, S. (2015), Engagement: Looking beyond the mirror to understand action understanding.

British Journal of Developmental Psychology.

King henry $1^{\text {st }}$ Street

doi: 10.1111/bjdp.12106, which has been published in final

form at

http://onlinelibrary.wiley.com/doi/10.1111/bjdp.12106/full

This article may be used for non-commercial purposes in

Portsmouth PO1 2DY, UK accordance with Wiley Terms and Conditions for SelfArchiving.

Email: vasu.reddy@port.ac.uk

${ }^{2}$ University of Parma

Department of Neuroscience

Via Volturno 39

43120 Parma, Italy

${ }^{3}$ Charité Universitätsmedizin, Berlin

Bernstein Centre for Advanced Neuroimaging

Philippstrasse 13, Haus 6

10117 Berlin, Germany

Email: sebouithol@gmail.com 


\title{
Engagement: Looking beyond the mirror to understand action understanding
}

\author{
Abstract \\ In this paper we argue that the current focus on mirroring as the route to explaining \\ the development of action understanding is misleading and problematic. It facilitates a \\ fundamentally spectatorial stance, ignoring engagement and dialogue; it focuses on \\ similarity between self and other and neglects difference; and it succumbs to the static \\ terminology of mechanism rather than a dynamic language of process. Contrary to \\ this view, dialogic exchanges are evident from the start of life, revealing the infants' \\ ability to engage with and respond appropriately to actions that are outside their own \\ motor repertoire. We suggest that engagement rather than mirroring better accounts \\ for many current findings in action understanding. The neurological evidence to date \\ shows that action perception involves a process of continuous synchronisation and \\ change, suggesting that it might be more fruitful for research and theory to look \\ beyond mirroring and instead adopt dynamic processual explanations of action \\ understanding within interaction.
}




\section{Introduction}

The argument that infants' understanding of others' actions originates in infants' own action capabilities (Hunnius \& Bekkering, 2014; Woodward \& Gerson, 2014) is both cogent and consistent with the majority of current views in developmental neuroscience. In essence, the argument is that the neural systems that underpin infants' own actions are strongly connected to, and indeed drive, infants' 'analysis' of others' actions. This claim appears to be both strongly supported by current evidence and logically unimpeachable. If action is prospectively controlled (and there is good reason to believe that it is) then there must be 'abstract' intentional (and prospective) relations between goal and own movement which, when present, must also be available to infants when they perceive others' movements in relation to potential goals. The claim is heavily grounded in neuroscience with discoveries of mirror mechanisms allowing the perception of intentional relations in others' actions on the basis of own action production. In all, despite some recent criticisms ${ }^{1}$, the claim seems compelling. So why is it problematic?

The problem becomes clear when one realises that there are at least three ways in which infants are exposed to others' actions. The infant could merely observe the frequent occurrence of an action by the other without involvement. The infant could observe the similarity of an action by the other to that within the infant's repertoire. The infant could feel and produce a response to an action by the other which is

\footnotetext{
${ }^{1}$ Recent criticisms of the mirroring theory of action understanding have argued that mirroring is in fact a byproduct of associative learning (Heyes, 2010), and not necessary for action understanding (Hamilton, 2009; Hickok, 2009).
} 
directed to the infant - even in the absence of the capacity to produce the original action.

The received interpretation of mirror mechanisms in action understanding the direct-matching hypothesis (Rizzolatti, Fogassi, \& Gallese, 2001) - proposes that by mapping the observation of another's action onto one's own motor repertoire, a first person experience of the observed action is created (Rizzolatti \& Sinigaglia, 2010). This means that although action mirroring can be embedded in interaction, it need not be. And while producing a similar action (i.e. imitation) may be based on action mirroring, producing a different response falls outside of the scope of such a mechanism.

In this paper we take issue with the claim that infants' capacity to understand an action is dependent on their capacity to produce the same action for three reasons: First, the claim is, despite the best intentions of its proponents, fundamentally spectatorial. The crucial feature in such a first-person or third-person account ${ }^{2}$ is the infant's perception of the similarity of the other's action to an action in her own repertoire. The infant is still an observer and analyser of the action, not necessarily a participant with it.

\footnotetext{
${ }^{2}$ Discussions about knowing other minds note the spectatorial stance implied by both first person and third person accounts (Costall, 2013; Leudar \& Costall, 2009). In both, the knower is fundamentally an observer of the other mind. In first person accounts the knowing is accomplished through either explicit analogy with the self or implicit simulation of the other within the self. In third person accounts the knowing is accomplished through deduction and theory applied to the observed behaviour. Both adopt a Cartesian rather than a Hegelian view of knowing (I. Markova, 1982), in which the knower is independent of that which is known.
} 
Second, dialogue between self and other needs difference - not identity - to be meaningful. Although neither similarity nor difference are absolute or categorical entities, mirroring explanations focus on similarity between self and other, while action understanding within dialogue would require us to focus on infant actions as responses to difference.

Third, mirroring explanations incline towards a focus on mechanism and static representation (i.e. a dedicated mechanism that produces a mental or motor representation similar to the one present in the observed actor). We argue that understanding action is a more fluid and dynamic process, without a pre-defined and clear endpoint. Cognitive neuroscience and developmental science are better off focusing on the role motor resonance plays in enabling the organism to respond to relevant features, and to engage in dialogue with it, than on the static recognition of isolated actions. Before we discuss evidence that action understanding is not best interpreted solely in terms of mirroring, we briefly discuss the (largely neuroscientific) background of the current interpretation.

\section{From neurons to mechanism}

As is widely known, mirror neurons were first discovered in area F5 of the ventral premotor cortex of macaque monkeys. Monkeys were seated with their heads and bodies fixed while watching objects being picked up, and grasping these objects themselves. Single neurons appeared to be selectively activated not only when the monkey grasped the object, but also when the experimenter grasped it. Di Pellegrino and colleagues hypothesized that "the actions performed by other monkeys must be a very important factor in determining action selection", explicitly relating their findings to response generation and social interaction. Fairly soon, however, the role 
attributed to these neurons shifted from action selection to action understanding (Gallese, Fadiga, Fogassi, \& Rizzolatti, 1996; Rizzolatti, Fadiga, Gallese, \& Fogassi, 1996) and 'mind reading' (Gallese \& Goldman, 1998), and mirror neurons were hypothesized to be the neural instantiation of a simulation of the observed action in a motor format (Gallese \& Sinigaglia, 2011; Goldman, 2006). This move from action selection to action understanding strongly facilitates an interpretation in terms of passive observation rather than active involvement.

As it is hard to establish mirroring at the single cell level in humans (but see Mukamel, Ekstrom, Kaplan, Iacoboni, \& Fried, 2010), the word 'mirror neuron' was generally omitted when discussing human motor activation during action observation. Instead, the notion of 'mirror system' or 'mirror mechanism' (Rizzolatti et al., 2001) provides a more neutral term to account for the activation of motor areas during action observation (including the ventral premotor cortex, and the rostral part of the intraparietal lobule, with the posterior superior temporal sulcus being its main visual input (Iacoboni \& Dapretto, 2006). By referring to these areas as the 'mirror system', or implementing a 'mirror mechanism', claims about the exact implementation at the single cell level are avoided. Although this agnosticism is praiseworthy, the particular notions of 'system' and 'mechanism' implied here do involve a crucial conceptual step: they suggest a confined entity that has the purpose of accomplishing a specific task: a mechanism for understanding others. Thus was born the idea of a dedicated mechanism for understanding observed actions by mapping them onto the observer's own motor repertoire. Since premotor areas are part of this action observation system, activation in these areas is easily interpreted as instantiating simulation of the observed actions. Indeed, TMS (Fadiga, Fogassi, Pavesi, \& Rizzolatti, 1995), fMRI (Buccino et al., 2001), MEG (Hari et al., 1998), and mu-suppression based EEG 
paradigms (Cochin, Barthelemy, \& Roux, 1999) showed activation in premotor and motor areas during action observation, and were interpreted within the framework of action understanding.

The idea of a mirror mechanism rapidly found its way into developmental science. As the motor repertoire develops during infancy, the resulting framework generates testable hypotheses for the development of action understanding. And indeed, previous motor experience alters perceptions of others' actions. Sommerville and colleagues (2005) showed that 3-month-olds who are given artificial motor experience of reaching and grasping - in contrast to 3-month-olds not given such experience - can detect the goal-directedness of the reaches of a disembodied adult arm. Woodward and colleagues (2002) were able to directly link age-related motor production abilities with perception of motor acts. This link was further established using eye tracking and EEG studies (Ambrosini et al., 2013; Cannon \& Woodward, 2012; Daum, Prinz, \& Aschersleben, 2011; Kanakogi \& Itakura, 2011).

In all, the evidence seems strongly in favour of the hypothesis that understanding patterns and meanings in others' actions comes from having such patterns and meanings in one's own actions, with the idea of a dedicated action mirroring system that develops with the observer's motor skills leaving little room for a different interpretation. Yet, there are reasons for re-thinking the developmental evidence and looking beyond the mirror for explanations of the development of action understanding.

\section{The importance of engagement: self and other as participants not spectators}

Our predominant social experience in the first year of life comes from situations where we are directly involved and often the direct recipients of others' actions and 
utterances. At any point in our lives, actions directed to us put us immediately in a difference pragmatic frame where a response of some sort - even if only to ignore the action - is demanded of us. They also involve us in an immediately emotional relation - arousing interest, dislike, attraction, joy, pain, indifference and so on. Although in older children and adults such emotional involvement can occur in spectators too - as in watching movies - they are far more typical of direct interactions and, we argue, developmentally crucial in early infancy.

Various neuroscientific studies have shown that being a recipient rather than an observer makes a difference to neural responses (Kampe, Frith, \& Frith, 2003; Schilbach, Eickhoff, Mojzisch, \& Vogeley, 2008; Schilbach et al., 2006). Performing an action - even one as simple as looking at a stimulus on a screen together with someone - affects brain activation (Hoehl, Michel, Reid, Parise, \& Striano, 2014). Joint looking evokes activity in a brain area argued to be involved in thinking about mental states, while solo looking does not (Schilbach et al., 2013). Interpersonal engagement reaches into the future as well: not only do the actions of a partner in a game cause greater motor activation than the actions of a non-partner (Kourtis, Sebanz, \& Knoblich, 2010), but observation of the actions of people with whom you have previously interacted produces greater sensorimotor activation than observation of the actions of people you haven't interacted with (Kourtis, Knoblich, \& Sebanz, 2013). At the simplest level, it seems that being engaged with another person in some way - whether by being called, being looked at, being smiled at or by doing (or having done) simple actions with them - has a fundamental impact on brain responses.

Engagement also leads to different neural activation in infants. Direct gaze to 4 and 5 month olds evokes early and increased gamma band activity compared to 
averted gaze (Grossmann, Johnson, Farroni, \& Csibra, 2007) and enhanced prefrontal cortex activity (Grossmann, Parise, \& Friederici, 2010). Using ERP studies, Farroni and colleagues (2004) found that in 4 month olds cortical processing of direct gaze is enhanced even when the face is averted; and there is better recognition of (upright) faces with direct gaze than with averted gaze (Farroni, Massaccesi, Menon, \& Johnson, 2007). Mutual gaze also enhances the possibility of learning about the world and the processing of objects (Parise, Reid, Stets, \& Striano, 2008; Reid, Striano, Kaufman, \& Johnson, 2004) and the neural processing of facial expressions (Striano, Kopp, Grossmann, \& Reid, 2006). Prior mutual gaze enhances faster saccades to the peripheral targets of others' gaze even in neonates (Farroni et al., 2004) and gaze following in 6 month olds (Senju \& Csibra, 2008). Being addressed in one way or another is also directly 'preferred' by adults (Schnell, Bluschke, Konradt, \& Walter, 2011) and by infants: two to five day old infants already look preferentially at frontal photographs of faces in which the eyes are oriented forwards (looking at the infant) than those in which the eyes are averted to the side (Farroni, Csibra, Simion, \& Johnson, 2002), also when using schematic faces (Farroni et al., 2004).

Together these findings suggest that that the phenomenon of being addressed is developmentally crucial and has broader implications than simply the detection of ostensive cues as argued by some (Csibra, 2007) - it draws the infant further into emotional involvement with the other and the other's interests, rather than only into analysing and interpreting the other's behaviour as cues. The findings converge on the idea that social cognition is not just normal cognition with more complexity added. Rather, they show that our brains are deeply social, and that a social setting alters even the most basic processes. Most of these findings focus on being addressed by gaze; being addressed by actions is likely to be much harder to avoid noticing and 
responding to and also shows increased brain activity in the relevant regions (Nagels, Kircher, Steines, \& Straube, 2015). The world of new-born and very young infants is particularly full of actions performed by adults upon or towards their faces, limbs, mouths and bottoms.

\section{Dialogue needs difference not similarity}

The infant's engagement with adults from birth has a dialogic character (Bateson, 1979; Trevarthen, 1977), revealing reciprocal interactions with mutual adaptation to each other's actions and orientations. From at least two months of age infants are capable of perceiving the temporal and affective contingencies between their own actions and orientations and others' responses (Bigelow, 1998; G. Markova \& Legerstee, 2006; McQuaid, Bibok, \& Carpendale, 2009; Nadel, Carchon, Kervella, Marcelli, \& Réserbat Plantey, 1999; Reddy, Chisholm, Forrester, Conforti, \& Maniatopoulou, 2007). Such contingencies must also be perceivable in the reverse direction - that is, the relatedness of their own responses to others' actions must also be perceptually manifest.

Dialogue needs a responsive voice - a different 'other' - in order to develop, not similarity. As Buber put it (Friedman, 1955) "Though the Thou is not an It, it is also not "another $I$. ." He who treats a person as "another $I$ " does not really see that person but only a projected image of himself." Even at 3 months infants prefer contingent responses to their own initiatives to be appropriate but different, rather than direct imitations of their acts (G. Markova \& Legerstee, 2006). In other words, to engage with another dialogically, you do need a different other. The complex embeddedness of infant actions in participatory dialogues from the early months is evident in face to face as well as care-taking and other playful interactions (Nadel et 
al., 1999; Raczaszek-Leonardi, 2013; Rossmanith et al., 2014), with infants not only responding to the adult acts they receive, but receiving further adult actions in response to their own acts.

From the first moments of life, the majority of infant experiences of others' actions are of adults performing actions on them which the infant cannot possibly accomplish: holding the legs to lift the bottom, wiping the eyes, cleaning the nose, stroking the face, putting the arm in a sleeve, holding the chest to lift the baby up and so on. Most of these actions are not part of the infant's action repertoire, but infants do respond to them, often emotionally and appropriately. From a mirroring perspective, such adult actions to the infant would be either irrelevant or incomprehensible to the infant. However, the few studies that exist which test actions directed to the infant suggest that there is a lot more understanding going on in the early months than can be explained by mirroring. Habituation studies of action awareness - considered to be less cognitively demanding than studies of 'on-line' anticipatory responses (Cannon \& Woodward, 2012) - show the earliest infant awareness by 5 months of age (Woodward, 1998) or 3 months with action training (Somerville, Woodward \& Needham, 2005). Studies using measures of anticipation show their earliest effects at 6 months of age (Ambrosini et al., 2013; Kanakogi \& Itakura, 2011). In all these studies, however, the infant was a mere spectator of adult actions directed to a distal object. Studies of actions where the infant is the recipient of the action yield earlier evidence of action awareness. By at least two months of age infants adjust their bodies by increasing its rigidity and by opening their arms when adults extend their arms to pick them up (Reddy, Markova, \& Wallot, 2013). Infants at 2 and 3 months cannot yet reach out with both arms in anything like the pick-up gesture, yet have little difficulty anticipating and adjusting to its specific meaning. In 
pre-school children with autism, on the other hand, where there is little difficulty with reaching out, anticipatory adjustments to being picked up have been reported to be absent or problematic (Kanner, 1943) suggesting that such anticipations may be connected to the perception of intentionality of actions. Similarly, unlike the anticipatory mouth opening of typically developing infants being fed with a spoon or indeed from a bottle or breast, children with autism do not open their mouths in anticipation of the approaching spoon (Brisson, Warreyn, Serres, Foussier, \& Adrien, 2012) ${ }^{3}$. Further, at 2 and 3 months anticipation of being picked up occurs with constant gaze to the mother's face rather than to her hands or away (Reddy et al., 2013), suggesting that this is not merely the anticipation of an impersonal event but of the action of a person (see Bruner, 1974 for a similar interpretation of the distinction between 'giving' with gaze to the hand and 'giving' with gaze to the other's face). Our argument is that the infant's responses both reveal and further build the infant's understanding of the adult's pick up act; the response itself illuminates and co-creates the meaning of the act. The mirroring framework has nothing to say about such clear instances of infant action understanding, as the observed action cannot be mapped onto the motor repertoire of the infant.

Neonatal imitation studies offer the richest (as well as the most controversial) source of experimental data about infant responses to actions towards themselves. Debates continue about whether the infants' 'imitative' responses to the actions

\footnotetext{
${ }^{3}$ One could object that preparing for the pick-up or the approaching spoon is not really understanding of the action, but a mere prediction of what will happen, and an associated response. But notice that the highly studied 'target prediction' - usually cast in terms of “goal understanding” - is just as easily explained in terms of predictions and associations (see Uithol \& Paulus, 2013; Uithol, van Rooij, Bekkering, \& Haselager, 2011).
} 
modelled by adults extend beyond tongue protrusion, whether they are really 'imitative', and how one can explain the processes involved in it (see for instance Jones, 2009). Nonetheless, one key point of interest is the nature of the engagement involved in these interactions. Three sets of studies from three different laboratories attest to the conversational nature of the exchanges. Infants attend intently to facial actions directed towards them by adults, but not all attentive infants perform 'imitations', and those that do, do so with a range of patterns - from single actions to a series of acts either with increasing or decreasing proficiency (Kugiumutzakis, 1998). These imitative acts may also be anticipations of or invitations to the model to perform, also occurring (with infant gaze to the model) when the model is still and is no longer modelling the act (Meltzoff \& Keith Moore, 1994; Nagy \& Molnar, 2004). As with adults (see Dumas, Martinerie, Soussignan, \& Nadel, 2012) even with very young infants, the role of model and imitator can be hard to tell apart. It has been argued that even imitative interactions are not merely imitative and that the actions themselves are never identical to those observed (Csibra, 2007). They often involve varying degrees of approximation and varying degrees of hesitation and change: responses to, rather than mimicking of, another person; unless done robotically, imitation is always a response (Uzgiris, 1981). Neonatal imitation can provide strong evidence of motor resonance and offer an explanation of how the infant recognises the similarity between actions observed and actions produced. However, regardless of one's take on it as imitation, these exchanges provide even stronger evidence of the neonate's interest in engaging with actions directed towards them and in ongoing dialogic interactions with others.

We offer one further example as evidence of appropriate responses by infants to acts outside of their own repertoire: infant laughter to deliberate, infant-directed 
acts of absurdity and silliness by adults. Adults engage in a range of acts to amuse babies - and the earliest successful acts tend to be absurd facial expressions and abruptly ending tones or repetitive sounds like 'brr-ing' the lips' (Sroufe \& Wunsch, 1972). From around 3 or 4 months of age infants can produce deep belly laughs to a range of adult acts directed towards them. Adult attempts at clowning tend to be wrapped up in a framework of smiling and laughter (Mireault et al., 2012) which is likely to be emotionally reassuring. Nonetheless, the adult acts that elicit such reactions and anticipations from infants can be entirely outside the infant's own motor repertoire. The intention and 'meaning' of these adult acts comes from the infant's own affective response to them and the ensuing dialogue, not from the motor resonance of the acts themselves (see also the affective embeddedness of joint attentional acts; Leavens et al., 2014).

Engagement affords a broader and relational level of explanatory framework of current findings than does mirroring. It accounts for learning from the experience of observed actions that are outside the infant's own repertoire as well as from those within; it accounts for perceived meaningfulness of observed actions under situations of motor constraint (Csibra, 2007); it accounts for findings that observational experience sensitises infants - they attend more specifically to specific features of pets if they have experience of pets at home, a finding that doesn't extend to human faces (Hurley \& Oakes, 2015); and it accounts for findings showing selective mirroring (Caggiano et al., 2012).

Arguments about the primacy of engagement in the development of mind knowledge (Reddy, 2003; 2008; 2011) claim that being directly addressed by 'other minds' is necessary for typical social cognition. They posit a gradually expanding awareness of aspects of mind emerging from direct experience with them in second- 
person interactions. Thus, another's attention directed to her allows the infant to experience attention and response by being the object of attention, before she can grasp the meaning of others' attention directed to other objects. From a simple grasp of attention directed to self, the infant comes to understand attention to other objects to parts of the infant's body within the first six months (such as in action games on the infant's hands and feet) to the infant's own actions from around 7 or 8 months of age (such as repeating funny faces or sounds or movements to re-elicit adult attention or laughter) before it can include objects in distal space between 9 and 12 months of age (such as following gaze to distal targets, and pointing). Similarly, understanding the goal-directedness of intentional actions, it is predicted, emerges from being the goal of others' intentional actions from the start of life. This experience, we argue, forms the basis upon which understanding goal-directedness to other objects emerges grasping actions directed towards other objects and grasping adults' intentions to modify the infant's own actions (Heimann \& Uithol, 2015; Reddy, 2015; Reddy et al., 2013).

These views predict that difficulties in atypical development stem partly from earlier difficulties in second person interactions, as well as predictions about the primacy of second person engagements in typical development. Neonatal imitation for instance, should be easier to obtain when the model addresses the infant with the act than when the act is simply witnessed, addressed to no one. Understanding the goal of a reach (when witnessing someone reach for an object, for instance) should not be easy to grasp if you have never been reached for yourself. Typical conceptual and inferential understanding of attention and goal-directedness must come from these experiences of being the object or goal. 


\section{Action understanding is a dynamic process}

In her critique of mirror system explanations of action understanding, Southgate (2013) argues that action production experience may provide better learning opportunities than action observation alone (suggesting that the absence of learning opportunities in a merely observed action, rather than absence of motor activation, is key to not understanding it). She argues that action production might lead to better learning about the goal object of the action (such as object names; Yu \& Smith, 2012), better retention of its information consequences (Begus, Gliga, \& Southgate, 2014) and possibly greater arousal. While her departure from mirror-based explanations of action understanding is a great leap forward, we believe her alternative still suffers from the spectatorial ghost that haunts the debate, framing her explanation in terms of cues and prediction. What her alternative does not quite touch on is that most infant action production experiences occur within pragmatic frames and long engagement histories, not only sensitizing infants to the specific actions of others but also drawing them into the contexts in which these actions make sense. By seeking a processual rather than a mechanistic explanation, various strands of cognitive science offer sources for an alternative interpretation of the finding of mirror neurons and motor resonance.

First, field theory (Lewin, 1951) and Gibsonian approaches have offered strong arguments for thinking of psychological phenomena in terms of process rather than mechanism. In their rejection of an animal-environment dualism they posited action fields with pre-existing or ongoing sociocultural tuning processes, avoiding the more typical analytic focus on representations, and on moments of 'here and now givenness' (Kadar \& Effken, 2005). Such a processual view steers interpretation away from the infant as analyser of observed action, towards a framework in which infant 
and actor engage in an action dialogue, through which understanding and meaning is created.

Second, dynamic systems theory offers a non-representational account of cognitive processes, focusing on processes that are dynamically linked to other processes (Beer, 2000; Thelen \& Smith, 1994). Instead of postulating an internal mental state that is causally responsible for the subsequent behaviour, this approach seeks the causes of behaviour in the interaction of various control processes both within and outside of the central nervous system, in dynamic interaction with external factors (Schurger \& Uithol, 2015; Shenoy, Kaufman, Sahani, \& Churchland, 2011). For action understanding, instead of inferring a mental state that could be responsible for the observed action (see Uithol, Burnston, \& Haselager, 2014 for problems with this framework), understanding consists of ongoing prediction and response generation within interaction.

Third, enactivism highlights the fact that cognition did not evolve for creating faithful representations about the external world, but to allow the organism to act appropriately. That is, mind is seen not as inhering in the individual, but as emerging and existing dynamically in the relationship between organisms and their surroundings (including other agents; McGann, De Jaegher, \& Di Paolo, 2013). It is recognized that the interaction process itself forms an irreducible domain of dynamics which can be constitutive of individual agency (De Jaegher \& Froese, 2009). According to Di Paolo and De Jaegher's 'Interactive Brain Hypothesis', (2012) when an individual interacts with others, the interaction processes would not function merely as perceptual input to ready-made mechanisms but would also play a role in shaping brain mechanisms for social interaction. 
Each of these approaches enables interpreting motor activation during action observation not merely in terms of 'resonance' (i.e. evoking the same motor representation in the observer), but in terms of interaction (Dumas, 2014) and participation in the creation of meaning. This mutual adaptation results in interactional synchrony to which both members contribute (Dumas, Nadel, Soussignan, Martinerie, \& Garnero, 2010). Next, these approaches predict that motor activation during action observation is not automatic and stable, but can be influenced by a variety of factors, most notably the interaction and the actor. This prediction is indeed supported by a volley of findings on both infants and adults. Hoehl and colleagues (2014) found desynchronisation in the alpha frequency range in ninemonth-old infants when looking at an object together with an adult during a social interaction involving eye contact. Interestingly, when infant and experimenter only looked at the object without engaging in eye contact, no such effect was observed. In adults, Oberman and colleagues (2007) showed that the mu-frequency is modulated by the degree of social interaction. Being the addressee of an action results in the largest suppression. Finally, motor resonance is response-dependent. NewmanNorlund et al. (2007) found greater activation in the right inferior frontal gyrus and the bilateral intraparietal lobules (areas typically associated with action mirroring) when participants had to perform a complementary action compared to an imitative action.

We interpret these findings as strong support for a process view of action understanding. Thinking in process terms forces us to recognise something ongoing rather than a snapshot, something changing and developing rather than static, and something open to experience rather than pre-determined. Our point here is that the phenomena of action understanding (both at behavioural and neural levels) are 
fundamentally emergent, contextual, open to experience and subject to change within engagement. Thus, thinking of action understanding itself as a process is different from thinking of it as a mechanism, and opens us up to different methods, evidence and explanations of action understanding.

\section{Conclusion}

We have argued that the current focus on mirroring as the route to explaining the development of action understanding is misleading and problematic. Instead, we believe that the predominant state of being is relational and involved or engaged, and that any complete account of (the development of) action understanding must take this engagement into account. If we treat interaction as a special case of actions, we are missing out on grasping a key source of experiences for infants' understanding of others' actions. When we move beyond the mirror and start viewing interaction as the more basic setting for social cognition and exposure to actions, we open our eyes to different methods, evidence and explanations. Action understanding takes place in a context of interaction in which meaning and sense-making emerge from an ongoing dialogic engagement.

\section{References}

Ambrosini, E., Reddy, V., de Looper, A., Costantini, M., Lopez, B., \& Sinigaglia, C. (2013). Looking Ahead: Anticipatory Gaze and Motor Ability in Infancy. Plos One, 8(7), e67916. http://doi.org/10.1371/journal.pone.0067916 
Bateson, M. C. (1979). The epigenesist of conversational interaction: A personal account of research development. In M. Bullowa, Before Speech The beginning of human communication (pp. 63-77). London.

Beer, R. (2000). Dynamical approaches to cognitive science. Trends in Cognitive Sciences, 4(3), 91-99.

Begus, K., Gliga, T., \& Southgate, V. (2014). Infants Learn What They Want to Learn: Responding to Infant Pointing Leads to Superior Learning. Plos One, 9(10), e108817. http://doi.org/10.1371/journal.pone.0108817

Bigelow, A. E. (1998). Infants' sensitivity to familiar imperfect contingencies in social interaction. Infant Behavior and Development, 21(1), 149-162.

Brisson, J., Warreyn, P., Serres, J., Foussier, S., \& Adrien, J.-L. (2012). Motor Anticipation Failure in Infants With Autism: a Retrospective Analysis of Feeding Situations. Autism, 16(4), 420-429. http://doi.org/10.1177/1362361311423385

Bruner, J. S. (1974). From communication to language — a psychological perspective. Cognition, 3(3), 255-287. http://doi.org/10.1016/0010-0277(74)90012-2

Buccino, G., Binkofski, F., Fink, G. R., Fadiga, L., Fogassi, L., Gallese, V., et al. (2001). Action observation activates premotor and parietal areas in a somatotopic manner: an fMRI study. European Journal of Neuroscience, 13(2), $400-404$.

Caggiano, V., Fogassi, L., Rizzolatti, G., Casile, A., Giese, M. A., \& Thier, P. (2012). Mirror neurons encode the subjective value of an observed action. Proceedings of the National Academy of Sciences. 
Cannon, E. N., \& Woodward, A. L. (2012). Infants generate goal-based action predictions. Developmental Science, 15(2), 292-298. http://doi.org/10.1111/j.1467-7687.2011.01127.x

Cochin, S., Barthelemy, C., \& Roux, S. (1999). Observation and execution of movement: similarities demonstrated by quantified electroencephalography. European Journal of Neuroscience, 11, 1839-1842.

Costall, A. (2013). Things that help us make what we are. In G. Sammut, P. Daanen, \& F. M. Mofhaddam, Understanding the Self and Others Explorations in Intersubjectivity and Interobjectivity (pp. 66-67). Abingdon.

Csibra, G. (2007). Action mirroring and action interpretation: An alternative account. In P. Haggard, Y. Rossetti, \& M. Kawato, Sensorimotor Foundations of Higher Cognition. Attention and Performance XXII (pp. 427-451). Oxford: Oxford University Press.

Daum, M. M., Prinz, W., \& Aschersleben, G. (2011). Perception and production of object-related grasping in 6-month-olds. Journal of Experimental Child Psychology, 108(4), 810-818. http://doi.org/10.1016/j.jecp.2010.10.003

De Jaegher, H., \& Froese, T. (2009). On the Role of Social Interaction in Individual Agency. Adaptive Behavior, 17(5), 444-460.

http://doi.org/10.1177/1059712309343822

Di Paolo, E. A. (2012). The interactive brain hypothesis. Frontiers in Human Neuroscience, 6(163), 1-16. http://doi.org/10.3389/fnhum.2012.00163/abstract Dumas, G. (2014). Towards a two-body neuroscience. Communicative \& Integrative Biology, 4(3), 349-352. http://doi.org/10.4161/cib.4.3.15110 
Dumas, G., Martinerie, J., Soussignan, R., \& Nadel, J. (2012). Does the brain know who is at the origin of what in an imitative interaction? Frontiers in Human Neuroscience, 6. http://doi.org/10.3389/fnhum.2012.00128

Dumas, G., Nadel, J., Soussignan, R., Martinerie, J., \& Garnero, L. (2010). InterBrain Synchronization during Social Interaction. Plos One, 5(8), e12166-10. http://doi.org/10.1371/journal.pone.0012166

Fadiga, L., Fogassi, L., Pavesi, G., \& Rizzolatti, G. (1995). Motor facilitation during action observation: a magnetic stimulation study. Journal of Neurophysiology, 73(6), 2608-2611.

Farroni, T., Csibra, G., Simion, F., \& Johnson, M. H. (2002). Eye contact detection in humans from birth. Proceedings of the National Academy of Sciences of the United States of America, 99(14), 9602-9605.

http://doi.org/10.1073/pnas.152159999

Farroni, T., Massaccesi, S., Menon, E., \& Johnson, M. H. (2007). Direct gaze modulates face recognition in young infants. Cognition, 102(3), 396-404. http://doi.org/10.1016/j.cognition.2006.01.007

Farroni, T., Massaccesi, S., Pividori, D., \& Johnson, M. H. (2004). Gaze Following in Newborns. Infancy, 5(1), 39-60. http://doi.org/10.1207/s15327078in0501_2

Friedman, M. S. (1955). Martin Buber: the life of dialogue.

Gallese, V., \& Goldman, A. (1998). Mirror neurons and the simulation theory of mind-reading. Trends in Cognitive Sciences, 2(12), 493-501.

Gallese, V., \& Sinigaglia, C. (2011). What is so special about embodied simulation? Trends in Cognitive Sciences, 15(11), 512-519. http://doi.org/10.1016/j.tics.2011.09.003 
Gallese, V., Fadiga, L., Fogassi, L., \& Rizzolatti, G. (1996). Action recognition in the premotor cortex. Brain, 119(2), 593-610.

Goldman, A. (2006). Simulating minds: the philosophy, psychology, and neuroscience of mindreading. Philosophy of mind series. Offord; New York.

Grossmann, T., Johnson, M. H., Farroni, T., \& Csibra, G. (2007). Social perception in the infant brain: gamma oscillatory activity in response to eye gaze. Social Cognitive and Affective Neuroscience, 2(4), 284-291.

http://doi.org/10.1093/scan/nsm025

Grossmann, T., Parise, E., \& Friederici, A. D. (2010). The detection of communicative signals directed at the self in infant prefrontal cortex. Frontiers in Human Neuroscience, 4, 201. http://doi.org/10.3389/fnhum.2010.00201

Hamilton, A. F. de C. (2009). Research review: Goals, intentions and mental states: challenges for theories of autism. Journal of Child Psychology and Psychiatry, $50(8), 881-892$.

Hari, R., Forss, N., Avikainen, S., Kirveskari, E., Salenius, S., \& Rizzolatti, G. (1998). Activation of human primary motor cortex during action observation: a neuromagnetic study. Proceedings of the National Academy of Sciences of the United States of America, 95(25), 15061-15065.

Heimann, K., \& Uithol, S. (2015). Participation Over Observation: The Roots of Action Understanding in Attunement. Journal of Consciousness Studies, 22(12), 45-48.

Heyes, C. M. (2010). Where do mirror neurons come from? Neuroscience and Biobehavioral Reviews. 
Hickok, G. (2009). Eight Problems for the Mirror Neuron Theory of Action Understanding in Monkeys and Humans. Journal of Cognitive Neuroscience, 21(7), 1229-1243.

Hoehl, S., Michel, C., Reid, V. M., Parise, E., \& Striano, T. (2014). Eye contact during live social interaction modulates infants' oscillatory brain activity. Social Neuroscience, 9(3), 300-308. http://doi.org/10.1080/17470919.2014.884982

Hunnius, S., \& Bekkering, H. (2014). What are you doing? How active and observational experience shape infants' action understanding. Philosophical Transactions of the Royal Society of London. Series B: Biological Sciences, 369(1644), 20130490-20130490. http://doi.org/10.1098/rstb.2013.0490

Hurley, K. B., \& Oakes, L. M. (2015). Experience and Distribution of Attention: Pet Exposure and Infants' Scanning of Animal Images. Journal of Cognition and Development, 16(1), 11-30. http://doi.org/10.1080/15248372.2013.833922

Iacoboni, M., \& Dapretto, M. (2006). The mirror neuron system and the consequences of its dysfunction. Nature Reviews: Neuroscience, 7(12), 942-951.

Jones, S. S. (2009). The development of imitation in infancy. Philosophical Transactions of the Royal Society B-Biological Sciences, 364(1528), 23252335. http://doi.org/10.1098/rstb.2009.0045

Kadar, E. E., \& Effken, J. A. (2005). From discrete actors to goal-directed actions: toward a process-based methodology for psychology. Philosophical Psychology, 18(3), 353-382. http://doi.org/10.1080/09515080500177358

Kampe, K. K. W., Frith, C. D., \& Frith, U. (2003). "Hey John”: Signals Conveying Communicative Intention toward the Self Activate Brain Regions Associated with 'Mentalizing,' Regardless of Modality. Journal of Neuroscience, 23(12), $5268-5263$. 
Kanakogi, Y., \& Itakura, S. (2011). Developmental correspondence between action prediction and motor ability in early infancy. Nature Communications, 2, 341 . http://doi.org/10.1038/ncomms1342

Kanner, L. (1943). Autistic disturbances of affective contact. Nervous Child, 2, $217-$ 250.

Kourtis, D., Knoblich, G., \& Sebanz, N. (2013). History of interaction and task distribution modulate action simulation. Neuropsychologia, 51(7), 1240-1247. http://doi.org/10.1016/j.neuropsychologia.2013.04.001

Kourtis, D., Sebanz, N., \& Knoblich, G. (2010). Favouritism in the motor system: social interaction modulates action simulation. Biology Letters, 6(6), 758-761. http://doi.org/10.1098/rsbl.2010.0478

Kugiumutzakis, G. (1998). Neonatal imitation in the intersubjective companion space. In S. Braten, Intersubjective communication and emotion in early ontogeny (pp. 63-88). Cambridge: Cambridge University Press.

Leavens, D. A., Sansone, J., Burfield, A., Lightfoot, S., Oâ Hara, S., \& Todd, B. K. (2014). Putting the "Joy" in joint attention: affective-gestural synchrony by parents who point for their babies. Frontiers in Psychology, 5. http://doi.org/10.3389/fpsyg.2014.00879

Leudar, I., \& Costall, A. (2009). Against theory of mind. Basingstoke [England] ; New York : Palgrave Macmillan.

Lewin, K. (1951). Field theory in social science: Selected theoretical papers. (D. Cartwright). New York, Harper.

Markova, G., \& Legerstee, M. (2006). Contingency, imitation, and affect sharing: Foundations of infants' social awareness. Developmental Psychology, 42(1), 132-141. http://doi.org/10.1037/0012-1649.42.1.132 
Markova, I. (1982). Paradigms, thoughtand language. Chichester: Wiley. Markus. http://doi.org/10.1111/j.1468-5914.1978.tb00405.x/abstract

McGann, M., De Jaegher, H., \& Di Paolo, E. A. (2013). Enaction and psychology. Review of General Psychology, 17(2), 203-209. http://doi.org/10.1037/a0032935

McQuaid, N., Bibok, M., \& Carpendale, J. (2009). Relation between maternal contingent responsiveness and infant social expectations. Infancy, 14(3), 390401.

Meltzoff, A. N., \& Keith Moore, M. (1994). Imitation, memory, and the representation of persons. Infant Behavior and Development, 17(1), 83-99. http://doi.org/10.1016/0163-6383(94)90024-8

Mireault, G., Poutre, M., Sargent Hier, M., Dias, C., Perdue, B., \& Myrick, A. (2012). Humour Perception and Creation between Parents and 3 to 6 month old Infants. Infant and Child Development, 21(4), 338-347. http://doi.org/10.1002/icd.757

Mukamel, R., Ekstrom, A., Kaplan, J., Iacoboni, M., \& Fried, I. (2010). SingleNeuron Responses in Humans during Execution and Observation of Actions. Current Biology, 20(8), 750-756.

Nadel, J., Carchon, I., Kervella, C., Marcelli, D., \& Réserbat Plantey, D. (1999). Expectancies for social contingency in 2 month olds. Developmental Science, 2(2), 164-173. http://doi.org/10.1111/1467-7687.00065

Nagels, A., Kircher, T., Steines, M., \& Straube, B. (2015). Feeling addressed! The role of body orientation and co speech gesture in social communication. Human Brain Mapping, n/a-n/a. http://doi.org/10.1002/hbm.22746 
Nagy, E., \& Molnar, P. (2004). Homo imitans or homo provocans? Human imprinting model of neonatal imitation. Infant Behavior and Development, 27(1), 54-63. http://doi.org/10.1016/j.infbeh.2003.06.004

Newman-Norlund, R. D., Van Schie, H. T., Van Zuijlen, A., \& Bekkering, H. (2007). The mirror neuron system is more active during complementary compared with imitative action. Nature Neuroscience, 10(7), 817-818.

Oberman, L. M., Pineda, J. A., \& Ramachandran, V. S. (2007). The human mirror neuron system: a link between action observation and social skills. Social Cognitive and Affective Neuroscience, 2(1), 62-66. http://doi.org/10.1093/scan/ns1022

Parise, E., Reid, V. M., Stets, M., \& Striano, T. (2008). Direct eye contact influences the neural processing of objects in 5-month-old infants. Social Neuroscience, 3(2), 141-150. http://doi.org/10.1080/17470910701865458

Raczaszek-Leonardi, J. (2013). Young children's dialogical actions:The beginnings of purposeful intersubjectivity, $1-14$.

Reddy, V. (2003). On being the object of attention: implications for self-other consciousness. Trends in Cognitive Sciences, 7(9), 397-402. http://doi.org/10.1016/S1364-6613(03)00191-8

Reddy, V. (2008). How Infants Know Minds. Harvard University Press.

Reddy, V. (2011). A gaze at grips with me. In Joint Attention New developments in psychology, philosophy of mind, and social neuroscience (pp. 137-157). Cambridge, MA: Joint Attention: New Developments in .... Reddy, V. (2015). Joining intentions in infancy. Journal of Consciousness Studies, $22(1-2), 24-44$ 
Reddy, V., Chisholm, V., Forrester, D., Conforti, M., \& Maniatopoulou, D. (2007). Facing the perfect contingency: Interactions with the self at 2 and 3 months. Infant Behavior and Development, 30, 195-212.

Reddy, V., Markova, G., \& Wallot, S. (2013). Anticipatory Adjustments to Being Picked Up in Infancy. Plos One, 8(6), e65289. http://doi.org/10.1371/journal.pone.0065289

Reid, V. M., Striano, T., Kaufman, J., \& Johnson, M. H. (2004). Eye gaze cueing facilitates neural processing of objects in 4-month-old infants. NeuroReport, 15(16), 2553-2555.

Rizzolatti, G., \& Sinigaglia, C. (2010). The functional role of the parieto-frontal mirror circuit: interpretations and misinterpretations. Nature Reviews: Neuroscience, 11(4), 264-274.

Rizzolatti, G., Fadiga, L., Gallese, V., \& Fogassi, L. (1996). Premotor cortex and the recognition of motor actions. Cognitive Brain Research, 3(2), 131-142.

Rizzolatti, G., Fogassi, L., \& Gallese, V. (2001). Neurophysiological mechanisms underlying the understanding and imitation of action. Nature Reviews: Neuroscience, 2, 661-670.

Rossmanith, N., Costall, A., Reichelt, A. F., LÃ³pez, B., Lopez, B., \& Reddy, V. (2014). Jointly structuring triadic spaces of meaning and action: book sharing from 3 months on. Frontiers in Psychology, 5, 1390. http://doi.org/10.3389/fpsyg.2014.01390

Schilbach, L., Eickhoff, S. B., Mojzisch, A., \& Vogeley, K. (2008). What's in a smile? Neural correlates of facial embodiment during social interaction. Social Neuroscience, 3(1), 37-50. http://doi.org/10.1080/17470910701563228 
Schilbach, L., Timmermans, B., Reddy, V., Costall, A., Bente, G., Schlicht, T., \& Vogeley, K. (2013). Toward a second-person neuroscience. Behavioral and Brain Sciences, 36(04), 393-414. http://doi.org/10.1017/S0140525X12000660

Schilbach, L., Wohlschlaeger, A. M., Kraemer, N. C., Newen, A., Shah, N. J., Fink, G. R., \& Vogeley, K. (2006). Being with virtual others: Neural correlates of social interaction. Neuropsychologia, 44(5), 718-730. http://doi.org/10.1016/j.neuropsychologia.2005.07.017

Schnell, K., Bluschke, S., Konradt, B., \& Walter, H. (2011). Functional relations of empathy and mentalizing: an fMRI study on the neural basis of cognitive empathy. NeuroImage, 54(2), 1743-1754. http://doi.org/10.1016/j.neuroimage.2010.08.024

Schurger, A. A., \& Uithol, S. (2015). Nowhere and everywhere: The causal origin of voluntary action. Review of Philosophy and Psychology.

Senju, A., \& Csibra, G. (2008). Gaze Following in Human Infants Depends on Communicative Signals. Current Biology, 18(9), 668-671. http://doi.org/10.1016/j.cub.2008.03.059

Shenoy, K. V., Kaufman, M. T., Sahani, M., \& Churchland, M. M. (2011). A dynamical systems view of motor preparation: Implications for neural prosthetic system design. Progress in Brain Research, 192, 33-58. http://doi.org/10.1016/B978-0-444-53355-5.00003-8

Sommerville, J. A., Woodward, A. L., \& Needham, A. (2005). Action experience alters 3-month-old infants“" perception of others" actions. Cognition, 96(1), B1B11. 
Southgate, V. (2013). Does infant behaviour provide support for the mirror neuron theory of action understanding? Consciousness and Cognition, 22(3), 11141121. http://doi.org/10.1016/j.concog.2013.04.008

Sroufe, L. A., \& Wunsch, J. P. (1972). The development of laughter in the first year of life. Child Development, 43(4), 1326-1344.

Striano, T., Kopp, F., Grossmann, T., \& Reid, V. M. (2006). Eye contact influences neural processing of emotional expressions in 4-month-old infants. Social Cognitive and Affective Neuroscience, 1(2), 87-94. http://doi.org/10.1093/scan/ns1008

Thelen, E., \& Smith, L. B. (1994). A dynamic systems approach to the development of cognition and action. Cambridge, MA: MIT Press.

Trevarthen, C. (1977). Descriptive analyses of infant communication behaviour. In H. R. Schaffer, Studies on mother-infant interaction (pp. 227-270). London.

Uithol, S., \& Paulus, M. (2013). What do infants understand of others' action? A theoretical account of early social cognition. Psychological Research, 78(5), 609-622. http://doi.org/10.1007/s00426-013-0519-3

Uithol, S., Burnston, D., \& Haselager, W. F. G. (2014). Why we may not find intentions in the brain. Neuropsychologia, 56, 129-139. http://doi.org/10.1016/j.neuropsychologia.2014.01.010

Uithol, S., van Rooij, I., Bekkering, H., \& Haselager, W. F. G. (2011). Understanding motor resonance. Social Neuroscience, 6(4), 388-397.

Uzgiris, I. C. (1981). Two Functions of Imitation During Infancy. International Journal of Behavioral Development, 4(1), 1-12.

http://doi.org/10.1177/016502548100400101 
Woodward, A. L. (1998). Infants selectively encode the goal object of an actor's reach. Cognition, 69(1), 1-34.

Woodward, A. L., \& Gerson, S. A. (2014). Mirroring and the development of action understanding. Philosophical Transactions of the Royal Society B-Biological Sciences, 369(1644), 20130181-20130181.

http://doi.org/10.1098/rstb.2013.0181

Woodward, A. L., \& Guajardo, J. J. (2002). Infants' understanding of the point gesture as an object-directed action. Cognitive Development.

Yu, C., \& Smith, L. B. (2012). Embodied attention and word learning by toddlers. Cognition, 125(2), 244-262. http://doi.org/10.1016/j.cognition.2012.06.016 